\title{
Research on the Linkage Database Marketing Mode under the Background of Big Data Era
}

\author{
Zhang Zhuoqing \\ Nanchang Institute of Science \&Technology,Nanchang 330108,China
}

Keywords: Marketing mode, Value chain, Linkage, Database, Big data.

\begin{abstract}
In order to improve the enterprises competitive advantage under the background of big data era, this paper puts forward a new linkage marketing database model, and the model relies on the cloud computing technology. Cloud computing nodes are assigned to each dealer by enterprises, so as to realize the big data exchange between distributors or between enterprises and distributors, and to ensure the smoothness of the mass marketing data transmission. Taking the FAW Volkswagen type linkage database marketing model as a case, this paper studies the marketing database model from the practice, to further verify the linkage database on the extension meaning of enterprise value chain and ecological aspects, which provides a technical guidance for the innovation management of enterprise database marketing mode.
\end{abstract}

\section{Introduction}

With the accelerated development of the network technology and information economy, various forms of data sources are more widely, application areas also continue to expand, advertised as "mass", "high speed", "variety" and "volatile" big data era drive the core of enterprise competition from resources to data, marketing has become function theory researchers and enterprise management based on data rather than creative [1-3]. In order to maximize the value of mining marketing in the era of big data, we can guarantee competitive advantage in the dynamic business environment, which need to carry out customer segmentation for the marketing data, establishing the investment cost and transmission efficiency and data model [4,5]. However, we should not only follow the imitation trend, the system falls into useless data transition collection and garbage information's transmission situation. In order to solve this problem, the enterprise relies on cloud computing platform, dealers as cloud computing node shares the distribution resources, which can improve marketing efficiency and ensure the smoothness of the data transmission.

\section{The Linkage Marketing Database based on Big Data Cloud Computing}

Cloud computing platform integrates with a huge cloud data processing network. Linkage type database is established under the background of the big data era, it needs support from the cloud. The cloud technology can improve a lot of parallel network nodes and servers, and companies use virtualization technology to expand each node and server. Each node and server can be assigned to lower level dealers, then the dealer's data is integrated by each platform, so as to improve the data storage and processing capacity [6-8]. The common cloud computing technology platform framework is shown in Figure 1.

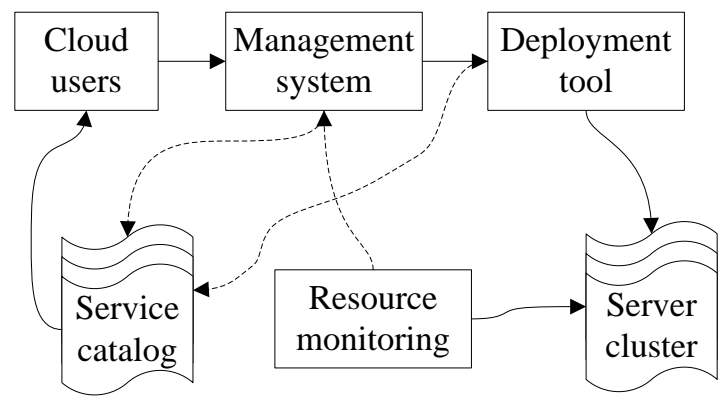

Fig. 1 The general cloud computing technology platform framework 
Figure 1 represents the general cloud computing platform framework, it is mainly computational resources system and server system, which can achieve computational resource dynamic deployment, configuration and scheduling, to achieve resource recycling. Server is responsible for sales data, customer management and enterprise information knowledge sharing, and cloud computing platform can meet the high-speed transmission of large data, to ensure the business communication process. In the platform, we introduce the data partitioning and parallel computing, which can improve data upload and download efficiency.

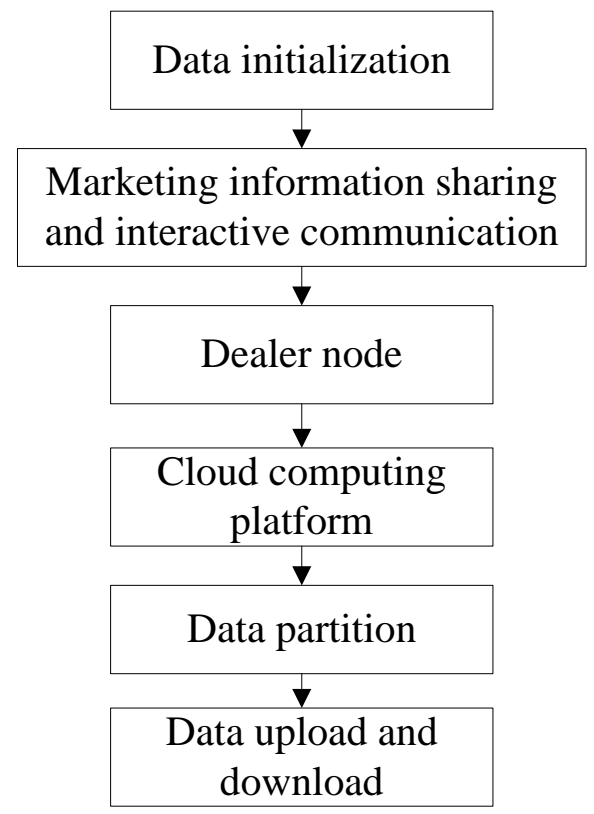

Fig. 2 The establishment process of marketing database

Figure 2 shows the establishment process of marketing database, it mainly takes the marketing information knowledge sharing and linkage type communication data as the basis. Using cloud computing technology establishes dealer cloud platform nodes, and it can accelerate the data upload and download in order to achieve data segmentation, so as to ensure the smooth of marketing database.

\section{Marketing Database Cloud Computing Algorithm under the Background of Large Data}

In order to affect the database creation under the background of big data, this system needs the help of cloud computing platform, the main design idea is to integrate computer resources and assign the enterprise each dealer, and the dealer can be according to the actual needs of the allocation resources [9-11]. Cloud computing resource allocation is multi-dimensional, and using multidimensional data C2MDSM model can realize the information interaction. Assuming that the end user is $i$, cloud computing provides the $i$-th network resources. In order to realize the resources rational allocation, this system introduces $0-1$ variables in i2-th, and its expression are as follows:

$$
Y_{i y}=\left\{\begin{array}{l}
1 \text { The } \mathrm{i}-\text { th network users are allocated } \mathrm{y} \text { network resources; } \\
0 \text { The } \mathrm{i} \text { - th network users are not allocated network resources. }
\end{array}\right.
$$

Then, cloud computing multidimensional mathematical model can be written in the form of formula (2). 


$$
\begin{aligned}
& \text { MinX }=\sum_{i=1}^{\mathrm{m}} \sum_{\mathrm{y}=1}^{\mathrm{m}} k_{\text {iy }} \mathrm{y}_{\text {iy }} \\
& \sum_{\mathrm{i}=1}^{\mathrm{m}} \mathrm{y}_{\text {iy }}=1 \quad \mathrm{y}=1,2 \mathrm{~L} \quad \mathrm{~m} \\
& \sum_{\mathrm{y}=1}^{\mathrm{m}} \mathrm{y}_{\text {iy }}=1 \quad \mathrm{i}=1,2 \mathrm{~L} \mathrm{~m} \\
& \mathrm{y}_{\text {iy }}=0 \text { or } 1 \quad i, y=1,2 \mathrm{~L} \quad \mathrm{~m}
\end{aligned}
$$

Assuming that a computer network user access to a cloud computing resources, the computing resources of the network users can be expressed matrix form as shown in formula (3).

$$
y=\left(y_{i y}\right)_{m \times m}=\left[\begin{array}{llll}
y_{11} & y_{12} & \mathbf{L} & x_{1 i} \\
y_{21} & y_{22} & \mathbf{L} & x_{2 i} \\
\mathbf{L} & & & \\
y_{i 1} & y_{i 2} & \mathbf{L} & x_{i i}
\end{array}\right]
$$

According to the fractal principle, the mathematical model of cloud computing can be written in the form of formula (4).

$$
\begin{aligned}
& \operatorname{Minx}=\sum_{i=1}^{4} \sum_{y=1}^{4} k_{i y} y_{i y}=21 y_{11}+18 y_{12}+\mathrm{L}+25 y_{43}+18 y_{44} \\
& \begin{cases}\sum_{i=1}^{4} y_{i y}=1 & y=1,2 \mathrm{~L} 3 \\
\sum_{y=1}^{4} y_{i y}=1 & i=1,2 \mathrm{~L} 3 \\
y_{i y}=0 \text { 或 } 1 \quad i, y=1,2 \mathrm{~L} 3\end{cases}
\end{aligned}
$$

Enterprise sharing knowledge information will be assigned to each dealer by using multidimensional fractal principle, and the use of multidimensional network nodes achieve linkage communication among dealers, companies and dealers, which guarantee the smoothness of the data transmission.

\section{The Construction of Cloud Computing Linkage Database Marketing}

System reconstruction and data management function parallel. Taking Volkswagen's sales as a case, competitive field has been broadened with the growing competition of the automotive industry, so the construction of core competition is becoming more and more important, and customer demand signal information has become the major competitive resource [12,13]. We should improve customer management system, analyze the depth excavation customer information and build a unique marketing advantage, and FAW Volkswagen begins the initial exploration of data management system and set out to establish database marketing model, the system can form a network of business strategic alliance mode by the use of fuzzy boundaries, thus completing the reconstruction of the value chain.

Linkage marketing database by value creation oriented. Value creation is a kind of management idea, it expresses that the value is reflected consumers' purchase and experience. In the production process, consumers have become participants according to the consumer experience collection and improvement production, so as to jointly create the value [14]. This concept is extended to value chain, and we can create a focus on value chain and the interests of all parties, so as to realize the linkage demand and each person's individual interests. In the value chain, we not only 
require the value chain leading enterprises to active concern other enterprises, but also need to ensure the smoothness of organizations and interactive platform and ensure the high-speed and efficient delivery of information.

The interactive marketing database of strengthening the common system and technology. In the FAW Volkswagen marketing database, the formation of learning system and create interest is brought about by the organization linkage relationships. In order to maintenance system information transfer and learning fluency, Volkswagen makes efforts from two aspects of support and system management efforts. In terms of suppliers, FAW Volkswagen technology investment mainly includes three aspects, the first is the supplier technology support, the second is management process planning, and the third is the supplier information grooming. In terms of dealer, FAW Volkswagen uses the database marketing of linkage type, to build product knowledge sharing platform and give great support of distributors from the technical level. For the customer level, we develop a oriented customer call center as a technical support, to maintain good communication with the public and customer. The company goes through the information platform to integrate and upgrade the IT system, ensuring the maintenance of information hub and the delivery of value chain information.

Enterprise knowledge sharing and profit sharing joint marketing database. The intensification of global competition makes many automotive companies no longer separate pursuit the formation of production efficiency and low cost, but to demand flexibility to adapt to market demand, so as to constantly breakthrough and technological innovation in order to survive. The automotive industry favors the global environment adaptation, its new knowledge management and creation comes from continuous independent learning, and linkage knowledge sharing and win-win benefit are the important means of the update value chain, which provide an important basis for the enterprise's long-term competitive. In recent years, in order to establish a long-term competitive advantage, we must establish the operational mode of the short-term benefits and long-term competition, so as to guide the development of enterprises with good. FAW Volkswagen uses linkage type of database marketing, which can obtain the production chain knowledge sharing and benefits, enterprise long-term competition and short-term gains, which has laid an important foundation for the long-term competitiveness of enterprises.

\section{Summary}

Today, the amount of data information is gradually expanding to obtain valuable information from the intangible information, which will become an important competitive advantage for the enterprise. To review the establishment of FAW Volkswagen database, we found that the relatively complete database marketing mainly includes the product information and knowledge internal database, and can carry out data mining data analysis system. Linkage marketing database system can integrate customer information, so people can obtain the customer's immediate needs and link the dealer's customer resources, completing the product introduction and technical Q \& A, thus completing the excavation of data depth.

\section{References}

[1] K.Y. Yang. Research on the construction of electronic commerce information ecosystem. Information science, 2014(3): 37-41.

[2] Z.Y. Ji, J.C. Tao. Research on the classification of logistics industry based on retail industry. Logistics technology, 2013(2): 18-20.

[3] J.E. Deng. The influence of open accounting on cross organizational cost management and its path. Accounting monthly, 2014(5): 32-35.

[4] X.H. Chen. Economic interests driving mechanism: the basic motive force of circular economy development based on Marxist interests concept analysis. Modern finance, 2013(9): 43-50. 
[5] X. Xiao, L. Zheng. Research on the construction of enterprise carbon accounting system under low carbon economy. Chinese population, resources and environment, 2014(08): 55-60.

[6] Y.Q. Wu. On the development strategy of the new library format. Modern information, 2014(12): 96-98.

[7] Y. He, W.Q. Wang, F. Xue. Research on massive data mining based on cloud computing. Computer technology and development, 2013, 23(2): 69-72.

[8] Y. Ding, Q.P. Yang. Y.M. Qian. Research on data mining platform architecture and its key technology based on cloud computing. ZTE communications, 2013,19(1) 53-60.

[9] K. Li, Z. Chang. The parallel data mining system design and implementation based on cloud computing. Microcomputer information, 2014, 27(6): 121-123.

[10] G.L. Sun, H.L. Qi. The spam filtering based on online scheduling logic regression. Journal of Tsinghua University, 2013, 53(5): 734-740.

[11] B.T. Liu. Research on the data mining algorithm based on rough set. China western science and technology, 2014, 10(14): 11-12.

[12] J. Zhu, W.H. Guan. Changzhou city sustainable development SD model from the perspective of industry. Geography and geo information science, 2014(5): 58-62.

[13] W.W. Dong, B.W. Li, Xiao, J. Liu. Analysis on business website information ecological system. Information theory and practice, 2014(8): 7-11.

[14] B.W. Li, Y. Xu. Research on network information ecological chain in Chinese shopping website. Modern library information technology, 2013(9): 67-73. 